\title{
Ethics worries over execution twist to Internet's 'visible man'
}

Washington. The 'visible man' is known to thousands of Internet users. An extremely detailed three-dimensional atlas of the male human body, it was placed on the Internet two years ago, launching the US\$1.4 million Visible Human Project of the US National Institutes of Health (NIH)'s National Library of Medicine (NLM). What fewer people know is that the digital images were taken from the cadaver of an executed Texas prisoner, Joseph Paul Jernigan.

Magnetic resonance images, radiographs and computerized tomography (CT) scans were made of his body, before it was frozen, sliced into 1,800 1-mm sections and photographed again.

The value of the anatomical database is undisputed. But specialists in medical ethics and lawyers working with inmates on death row say the use of an executed man raises disturbing questions.

Jernigan was aged 39 in 1993 when he was executed by lethal injection in Huntsville, Texas, for killing an elderly man, Edward Hale, during a burglary in 1981. Jernigan donated his body to science. His signed consent left his body to the Anatomical Board of the State of Texas.

Vic Spitzer, an anatomist who is one of the two principal investigators on the project at the University of Colorado Medical Sciences Center, says that the use of an executed man was a boon, in that the body was fresh, and allowed the best possible magnetic resonance images and CT scans.

'Still warm' might be a more accurate description. The anatomical board arranged to pick up the body immediately after the execution. They took it to a funeral home in Huntsville for early preparations and then put it on a charter jet to Denver where it was met by the Colorado researchers. About eight hours after the execution, they began taking images of the corpse.

"It was extremely convenient," says Michael Ackerman, the NLM official overseeing the project. Spitzer adds: "It's very difficult to find an intact, non-traumatized, non-pathologic cadaver. I'm not condoning execution. But I don't believe in wasting resources either."

Andrew F. Payer, secretary of the anatomical board, insists that the use of an executed man raises no ethical dilemma. The process "was in the letter of the law of the state of Texas. There was good intent both on $\mathrm{Mr}$ Jernigan's [side] and ours."

Payer says some reservations were expressed by NLM staff who feared a "public relations nightmare". He advised NLM

that it should follow the standard procedure of releasing the cause of death of the donated body - "a drug overdose" - but not Jernigan's identity.

Although Jernigan donated his body to science, the issues raised by its use in the online anatomical kit are many and contentious. Ethics specialists and prisoners' advocates question whether a prisoner on death row can be considered to be in a fit

\section{IMAGE UNAVAILABLE FOR COPYRIGHT REASONS}

An important resource: Jernigan's feet immortalized.

state to give free and informed consent.

George Kendall, a staff attorney with the Legal Defense Fund, a civil rights law firm, says: "A decision made under those circumstances would hardly be voluntary. When you're ready to be executed, you're hardly in the frame of mind to make some sort of long-term judgement."

Kendall is also concerned that donations could be "very easily abused" by prison officials and medical researchers. Arthur Caplan, the director of the Center for Bioethics at the University of Pennsylvania, agrees: "The question is, is it fair to use someone in that setting for research?"

Caplan argues that the possibility of coercion is "always there" when dealing with prisoners whose "liberty and choice is limited by being on death row".

Others question the validity of Jernigan's consent on the grounds that he was unaware of how his body would be used. Marcel LaFollette, a research professor at George Washington University in Washington DC who specializes in ethics and science policy, asks: "Did the consent include knowledge that he's going to be uploaded on the Internet and downloaded into everyone's personal computer?"

Offering inmates on death row the option of donating their bodies to science might encourage them to give up their efforts to appeal, and to "sign their own death warrants," claims Palmer Singleton, a death row lawyer at the Southern Center for Human Rights, a group that argues against capital punishment. "The more outs that you give them for bringing a quick end to what has been a terrible ordeal, the more you run the risk of covering up substantial profound wrongs."

Some ethics specialists consider that the use of Jernigan's body was ethical, provided he gave his consent voluntarily. "I don't believe [free and] informed consent is 을 meaningless on death row," says David $\sum$ DeGrazia, a biomedical ethicist at George Washington University. Similarly, Spitzer describes as "absurd" complaints about the legitimacy of consent in the case. "It's a phenomenal gift of peo2 ple that donate their bodies to science

$s$ and teaching. I hate to see that gift distorted by a process of someone that happens to be on death row."

Nonetheless, Spitzer says that his group "consumed a lot of hours of worrying and discussion" about the ethics of the situation. They turned to NLM, where senior staff "couldn't find any ethical or legal problems" according to Ackerman.

Later, however, NLM "had a real problem with it", says Spitzer. Concerned that Jernigan's family might sue, the library asked the Texas board to seek its approval. Payer refused. "There was no reason to go back to the family," he says. "Everything was done up front, and all according to the rules."

Mark Ticer, a lawyer who represented Jernigan, also dismisses the criticism. When Jernigan told Ticer of his intention to donate his body to science "a month or so" before the execution, he did not "feel like somebody was with a gun to his head forcing him to do it", says Ticer. The donation was "the only way that he felt like he could give something back for what he had taken". Wilmer Hale, a nephew of the man Jernigan murdered, also applauds the donation as "a good thing".

Jernigan's legacy to science is being seen by people around the world. The 55 gigabytes of full-colour 'Visible Human' images can be downloaded free from the Internet, provided users obtain a licence from NLM and credit it for any use made of the material. Around 600 individuals, corporations, high schools, universities and medical schools in 26 countries now have licences.

Jernigan has now been joined in cyberspace by the 'Visible Woman', an anonymous 59-year-old Maryland woman who died of a heart attack. Meredith Wadman 